\title{
O impacto da política comercial da União Europeia sobre as exportações brasileiras de hortifrúti
}

\author{
Mygre Lopes da Silva" \\ Daniel Arruda Coronel** \\ Reisoli Bender Filho***** \\ Rodrigo Abbade da Silva*****
}

\begin{abstract}
Resumo
Este estudo visa analisar efeitos da redução das barreiras comerciais da União Europeia para o setor exportador brasileiro de frutas, vegetais e nozes, especificamente, quanto à eliminação de barreiras tarifárias e não tarifárias. Para tal, fez-se uso do Modelo de Equilíbrio Geral Computável. Foram simulados dois cenários: a liberalização completa e as reduções das barreiras comerciais das exportações de hortifrúti do Brasil para a União Europeia conforme proposto pela Rodada de Doha. Os resultados indicaram que, para o Brasil, em ambos os cenários, há crescimento da quantidade produzida, das exportações e importações e dos preços domésticos do setor.
\end{abstract}

Palavras-chave: Exportações. Frutas. Vegetais. União Europeia. GTAP.

* Mestre em Administração. Doutoranda do Programa de Pós-Graduação em Administração da Universidade Federal de Santa Maria. Bolsista da Comissão de Aperfeiçoamento de Pessoal do Nível Superior. E-mail: mygrelopes@gmail.com

** Doutor em Economia Aplicada. Professor adjunto do Programa de Pós-Graduação em Administração da Universidade Federal de Santa Maria. Diretor da editora da Universidade Federal de Santa Maria. Bolsista de Produtividade do Conselho Nacional de Desenvolvimento Científico e Tecnológico. E-mail: daniel.coronel@uol.com.br / Homepage: www.daniel.coronel.com.br

*** Doutor em Economia Aplicada. Professor adjunto do Programa de Pós-Graduação em Administração da Universidade Federal de Santa Maria. E-mail: reisolibender@yahoo.com.br

**** Bacharel em Ciências Econômicas. Mestrando do Programa de Pós-Graduação em Administração da Universidade Federal de Santa Maria. Bolsista da Comissão de Aperfeiçoamento de Pessoal do Nível Superior. E-mail: abbaders@gmail.com

http://dx.doi.org/10.5335/rtee.v22i47.6811

Submissão: 31/05/2016. Aceite: 08/09/2016. 


\section{Introdução}

O comércio internacional de produtos do agronegócio é importante gerador de divisas, representando uma atividade responsável por manter o equilíbrio da balança comercial (CRUVINEL, 2009). Os estudos de comércio internacional frequentemente abordam pesquisas sobre soja, milho, minérios, entre outros produtos, embora sejam escassas as que tratam do setor de hortifrúti.

Verifica-se que a exportação desse setor gera renda, que é responsável por impulsionar as atividades e modernizar o setor nos últimos anos. Houve uma queda na área plantada de 5\% e aumento da produtividade de $32 \%$ entre 1995 a 2005 . Os ganhos em produtividade decorreram dos melhoramentos tecnológicos e gerenciais das propriedades, dos ganhos de escala, da consolidação de novas regiões produtoras e da abertura do setor ao mercado externo (BOTEON, 2006).

O mercado europeu destacou-se pela demanda de produtos hortícolas e frutícolas de 1999 a 2013, período em que a participação média no total exportado pela União Europeia (UE) foi de $24,42 \%$ e 54,2\%, respectivamente (ANÁLISE DAS INFORMAÇÕES DE COMÉRCIO EXTERIOR, 2013). Pode-se ressaltar que para o setor de frutas, a União Europeia é o principal destino desses produtos.

A elevada demanda europeia por produtos hortícolas e frutícolas pode estar relacionada com aspectos socioeconômicos, como a faixa etária dos indivíduos, o nível de escolaridade e o número de bens no domicílio, por exemplo. O consumo de frutas e vegetais é maior à medida que esses indicadores se elevam (JAIME; MONTEIRO, 2005; CIOCHETTO; ORLANDI; VIEIRA, 2012). Na medida em que a União Europeia é uma economia desenvolvida, justifica-se a procura por esses bens no mercado brasileiro.

Contudo, cabe destacar que a imposição de barreiras tarifárias e não tarifárias torna as frutas e vegetais brasileiros mais caros no mercado internacional e exige maior padrão de qualidade ao produto enviado. As principais barreiras não tarifárias utilizadas pelos países são cotas e restrição voluntária às exportações, já as novas barreiras comerciais são técnicas, ecológicas, burocráticas, sanitárias e fitossanitárias (AZÚA, 1986; MAIA, 2001). Para as exportações brasileiras de frutas e vegetais para o mercado europeu, as principais barreiras incidentes são as fitossanitárias, de padronização na finalização do produto, além das barreiras tarifárias e de subsídios à produção e exportação.

Ao discutir esses aspectos, este trabalho busca analisar os possíveis impactos das políticas comerciais da União Europeia para o setor exportador brasileiro de frutas e vegetais. Com esse estudo, pretendeu-se responder à seguinte pergunta: reduções e/ou eliminações das barreiras tarifárias e não tarifárias pela UE alavancariam as exportações brasileiras de frutas e vegetais? 
Com essa questão, buscou-se melhor compreender os possíveis fatores inerentes à competitividade das exportações brasileiras de frutas e vegetais, o que, entre outros aspectos, contribui para a formulação de políticas econômicas visando a uma maior competitividade e inserção internacional. A promoção do consumo de frutas e vegetais, devido aos aspectos nutricionais e de manutenção de uma alimentação de qualidade nas economias desenvolvidas, como nos países da UE, propicia a ampliação desse nicho de mercado, com elevação da demanda por frutas e vegetais brasileiros.

É importante ressaltar que ainda são incipientes os estudos que tratam do setor exportador de frutas e vegetais em relação a possíveis políticas tomadas pelos principais demandantes dos produtos, o que apresenta o aspecto inovador deste trabalho. Além disso, são praticamente inexistentes estudos sobre o comércio internacional brasileiro de produtos hortícolas, que são necessários para a melhor articulação das cadeias produtivas e acesso a outros mercados.

$\mathrm{O}$ artigo está estruturado em cinco seções, além desta Introdução. Na segunda seção, é apresentado o referencial teórico, na terceira, apresentam-se os aspectos metodológicos, na quarta, os resultados são analisados e discutidos e, por fim, na quinta, são delineadas as principais conclusões da temática explorada.

\section{Referencial teórico}

Nesta seção, apresentam-se os principais argumentos da Teoria da Integração Econômica, bem como suas fases ao longo do processo de integração. Além disso, analisam-se os efeitos estáticos da integração econômica, da criação e do desvio de comércio. Posteriormente, analisam-se as principais barreiras ao livre comércio.

\subsection{A formação de blocos econômicos}

A integração comercial entre os países ocorre de duas formas: por meio de negociações multilaterais, no sistema Gatt/OMC (General Agreement on Tariffs and Trade ${ }^{1 / O r g a n i z a c ̧ a ̃ o ~ M u n d i a l ~ d o ~ C o m e ́ r c i o), ~ o u ~ p o r ~ m e i o ~ d e ~ a c o r d o s ~ r e g i o n a i s . ~ A ~ p r i-~}$ meira forma promove ganhos de bem-estar e eficiência, de acordo com as teorias de comércio internacional, enquanto que para a segunda não há concordância teórica a respeito da ocorrência de ganhos ou perdas (MORAIS, 2005).

A integração econômica pode ser entendida como uma forma de cooperação econômica entre determinadas regiões, que tem como principal objetivo dos acordos e processos de integração a criação de mercados maiores, eliminando obstáculos aos 
fluxos de mercadorias, fatores e serviços entre países, nos moldes da teoria clássica, nos quais os mercados maiores operam com maior eficiência (VIEIRA, 2006).

Contudo, há divergências em relação à abrangência dos acordos regionais entre os países, na medida em que existem diferentes graus de integração bem como diferentes objetivos. Esses acordos econômicos ajudam a promover um comércio mais livre além de evitar conflitos comerciais destrutivos, com base em retaliações (KRUGMAN; OBSTFELD, 2005).

Em outra perspectiva, a integração regional tende a incentivar a especialização das nações na produção de bens que possuam vantagens comparativas. A redução (ou eliminação) de barreiras resulta em aumento da competição, o que afeta a estrutura produtiva dos países participantes do acordo. Destacam-se os ganhos com economias crescentes de escala, dada a tendência à especialização somada ao crescimento do tamanho do mercado (BARCELLOS NETO, 2002). Na Figura 1, destacam-se as fases do processo de integração econômica. ${ }^{2}$

Figura 1 - Fases da integração econômica entre países e/ou regiões

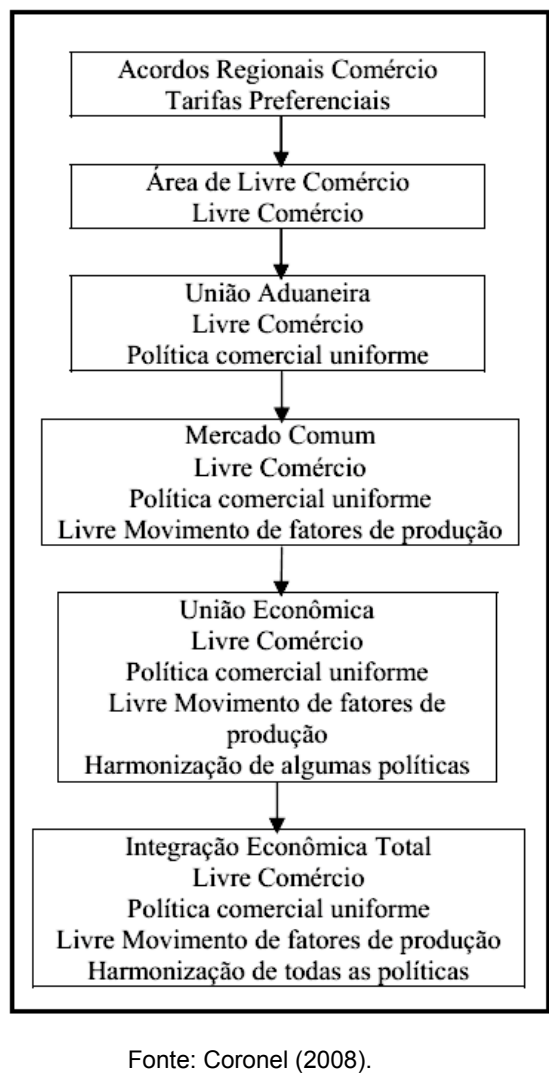

Teoria e Evidência Econômica - Ano 22, n. 47, p. 270-295, jul./dez. 2016 
O aumento da eficiência e a abertura comercial tornam a região inserida em blocos e/ou acordos comerciais mais atrativa ao aumento do fluxo de investimentos estrangeiros diretos, o que se reflete na migração de capital em direção aos membros do acordo (SALVATORE, 2000). Ressalta-se também a alteração nos termos de troca, decorrente da redução dos preços em função do acirramento competitivo, pelos ganhos de especialização e de escala, além da redução dos custos de transação devido à menor distância entre os mercados fornecedores, produtores e consumidores.

Porém, destaca-se que as pressões de grupos de interesse, os ciclos políticos e a interrupção das etapas do processo bem como o forte poder de mercado adquirido pelos participantes dos acordos comerciais podem reduzir os possíveis ganhos gerados (BALDWIN, 1989; MAGEE, 1997; BARCELLOS NETO, 2002).

\subsection{Efeitos da integração econômica: criação e desvio de comércio}

Por meio dos benefícios e dos custos gerados pela formação de blocos econômicos, Viner (1950) propôs os conceitos de criação e de desvio de comércio. A primeira ideia trata do aumento das importações de uma mercadoria de um país pertencente ao bloco por meio de reduções tarifárias, mesmo que isto implique queda de produção doméstica. Isso elevará o bem-estar das nações integrantes porque acarreta maior especialização na produção com base nas vantagens comparativas, assim como das nações não integrantes, pois parte do aumento dessa receita transforma-se em importações crescentes de outros países (SALVATORE, 2000).

Para compreender melhor o conceito de criação de comércio, supõe-se a formação de uma área de livre comércio entre dois países, A e B, em que apenas os produtos originados no interior do bloco podem circular livremente. Considere-se que o país A é o país exportador e B, o país importador, "t" é a tarifa imposta antes do acordo, "S" e "D" são as curvas de oferta e de demanda de um produto qualquer do país B.

Após a liberalização das tarifas intrabloco, o preço do bem produzido em A e importado por B reduz-se de "p0" para "p1", de acordo com a Figura 2. A redução de preço, ocasionada pela eliminação da tarifa "t", resulta em um aumento nas quantidades de consumo do bem, representado pela área "p0fgp1", por meio de um duplo ganho por parte dos agentes: preço menor e maior quantidade consumida (SALVATORE, 2000). 
Figura 2 - Criação de comércio

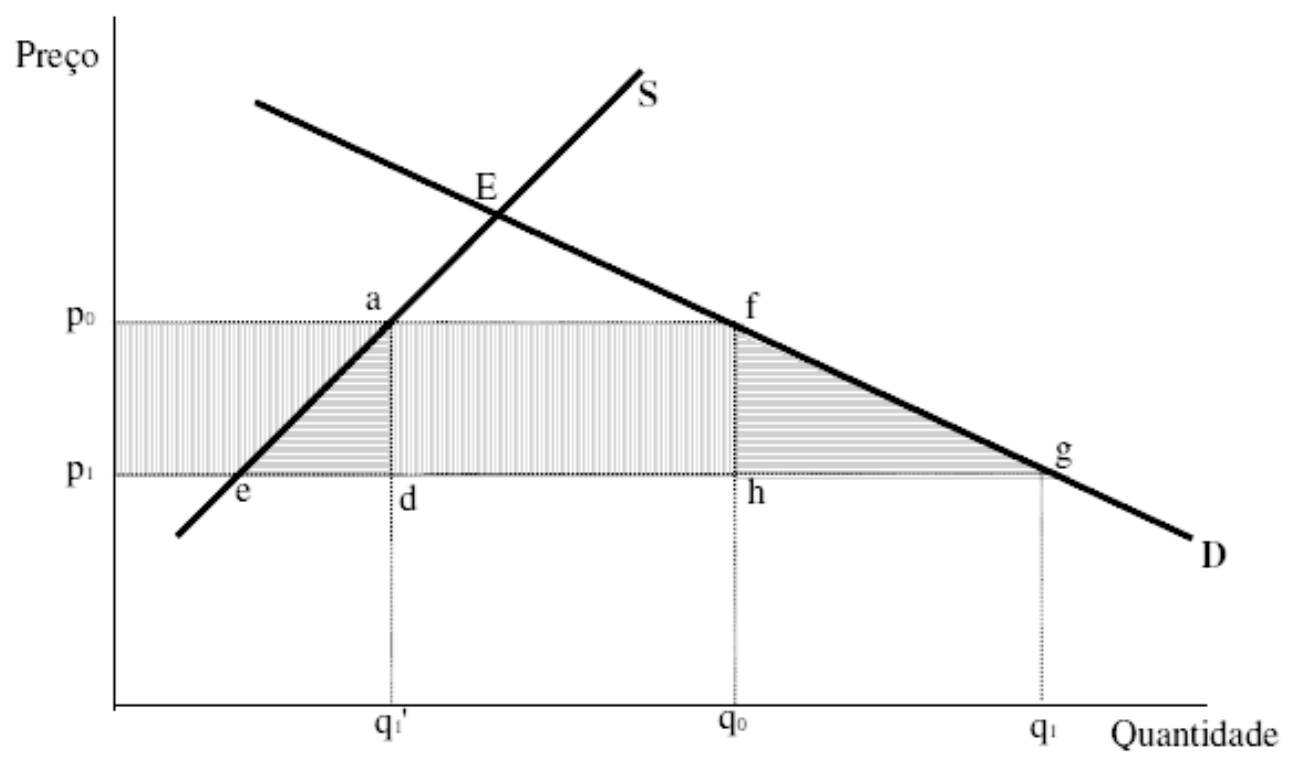

Fonte: Salvatore (2000).

Contudo, apenas parte dessa área representa o ganho líquido para a nação B. O retângulo "afhd" refere-se à perda tarifária pelo país B e a área representada por "p0aep1" expressa uma dedução de renda ou do excedente do produtor.

Verifica-se que a área de ganhos é maior do que a área de perdas, o que resulta em um ganho líquido para o país B composto por dois efeitos: o efeito produção e o efeito consumo. O primeiro consiste no deslocamento da produção de bens menos eficientes do país B para a produção de bens mais eficientes vindos da nação A. $\mathrm{O}$ efeito produção está representado por "ade”. O segundo, o efeito consumo, representado pelo triângulo "fgh", é resultado do aumento no consumo dos indivíduos da nação B. A soma de ambos os efeitos implica ganhos de bem-estar, ou seja, o efeito de criação de comércio (RUBIN, 2005).

Em suma, os ganhos de bem-estar são representados pelo aumento do consumo interno de bens, produzidos a preços mais baixos, importados de países que apresentam vantagens comparativas em sua produção, com custos mais reduzidos em relação à produção doméstica (CAVES; FRANKEL; JONES, 2001).

O segundo conceito abordado nessa seção é o de desvio de comércio, que acontece quando há um deslocamento das importações de uma nação fora do bloco para uma que participa dessa aliança. Isso ocorre devido à eliminação de tarifas entre 
os países-membros, tornando-se mais vantajoso transacionar com um produtor menos eficiente, o que acarreta perda de bem-estar da sociedade (BARCELLOS NETO, 2002). A Figura 3 ilustra essa situação.

Figura 3 - Desvio de comércio

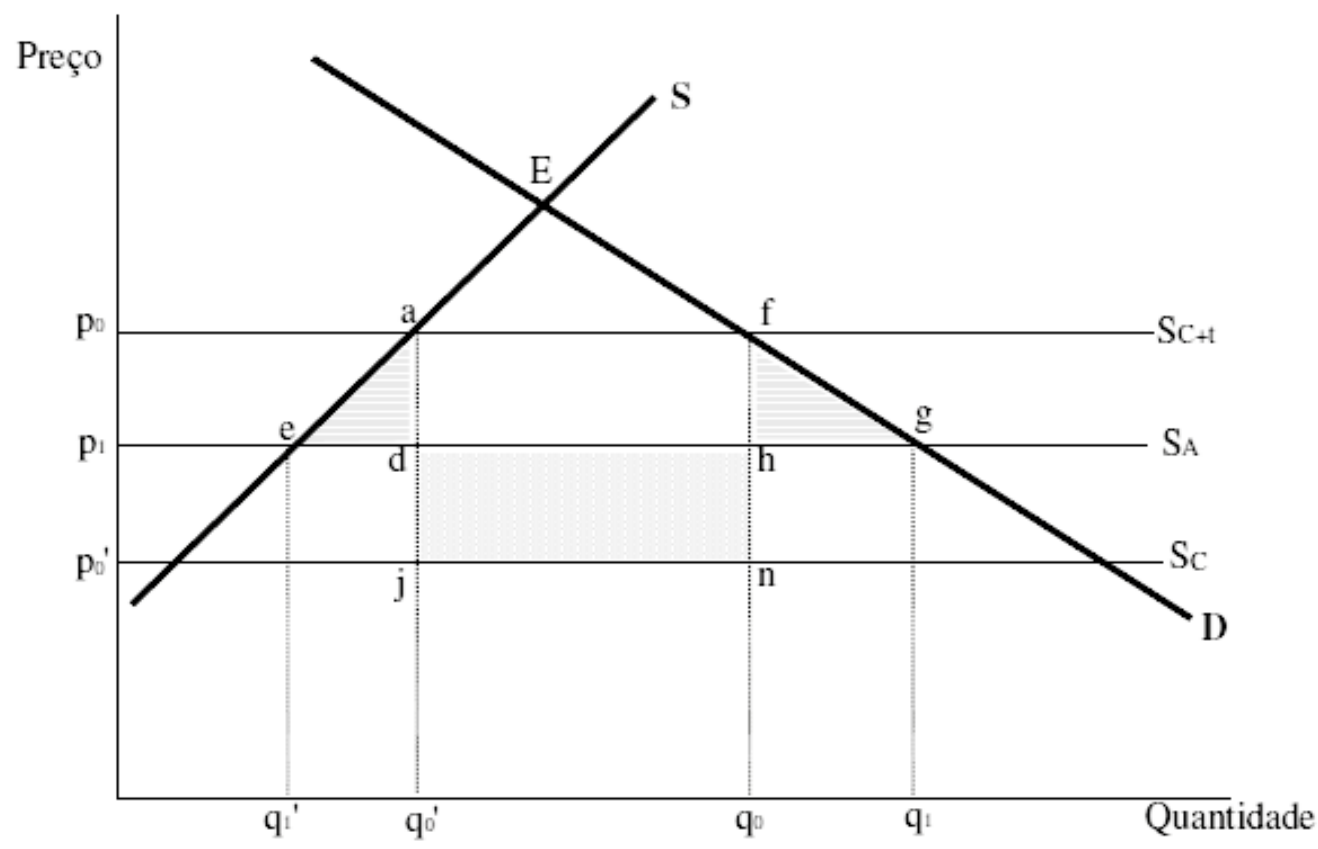

Fonte: Salvatore (2000).

Supondo-se que exista um terceiro país não parceiro, o país $\mathrm{C}$, e que, inicialmente, " $\mathrm{S}_{\mathrm{C}} \mathrm{e}$ "p0" sejam a curva de oferta, perfeitamente elástica, e o preço do produto ofertado pelo país $\mathrm{C}$, respectivamente.

Após um acordo de livre comércio entre os países A e B, o preço do produto ofertado pelo país C fica relativamente mais caro, igual a "p0", e a curva de oferta " $\mathrm{S}_{\mathrm{C}+\mathrm{t}}$ " de produtos de origem extrabloco tende a ser mais elevada. Nesse caso, o país $\mathrm{C}$, que é mais eficiente na produção do produto em questão, continua sofrendo restrições tarifárias igual a " $\mathrm{t}$ ".

O país B passa a desviar suas importações do país C, que é mais eficiente, para importações do país parceiro a um preço de oferta menos eficiente, dado por “p1”. Essa substituição de supridores, que acarretará aumento do volume exportado entre os países parceiros, o que, por sua vez, gera desvio de comércio ou perda de bem-estar, igual à área do retângulo "dhnj” (RUBIN, 2005). 
Verifica-se que o deslocamento da produção dos produtores mais eficientes não integrantes do bloco para os produtores menos eficientes que dele participam causa uma deterioração da alocação internacional dos recursos e afastamento da produção das vantagens comparativas (SALVATORE, 2000). A formação do bloco comercial é desejável apenas se os ganhos resultantes da criação de comércio forem maiores que as perdas do desvio de comércio (KRUGMAN; OBSTFELD, 2005).

Contudo, o aumento da participação das trocas intrarregionais pode ser gerado por melhorias efetivas de produtividade de algum país, que não possuem necessariamente qualquer vinculação com incentivos ou distorções tarifárias (BARCELLOS NETO, 2002). Em suma, quanto maior a área abrangida pelo bloco econômico, quanto mais países o integrarem e quanto mais competitivos os países membros, maior será a probabilidade de predominância da criação de comércio sobre o desvio de comércio (ROBSON, 1985).

Pode-se flexibilizar a proposta original de Viner, e desse modo, a criação de comércio pode ser entendida como um crescimento mais do que proporcional do comércio intrabloco, o que permite o aprofundamento do processo de integração entre os países membros. De forma semelhante, a destruição de comércio acontece quando há um crescimento menos do que proporcional do comércio intrabloco (OLIVEIRA et al., 2009). Porém, deve-se destacar a necessidade de isolar-se a influência das demais variáveis, como preços, taxa de câmbio, ganhos de produtividade, que podem influenciar os efeitos de comércio pós-integração (VASCONCELOS, 2001).

\subsection{Barreiras ao livre comércio}

As barreiras comerciais são os principais empecilhos ao laissez-faire, e são aplicadas com o intuito de proteger as economias nacionais. No entanto, existem diversas formas de protecionismo, uma delas é a tarifa, um imposto cobrado quando um bem é importado (KRUGMAN; OBSTFELD, 2005).

As tarifas é a forma mais utilizada para um país proteger a economia e seus efeitos são distintos, pois os produtores se beneficiam, embora os consumidores sejam prejudicados, visto que pagam um preço mais elevado pelas mercadorias (BRUM; HECK, 2005). As tarifas podem ser de três tipos: ad valorem, específicas e compostas. De acordo com Salvatore (2000), as tarifas ad valorem são expressas como uma porcentagem fixa do valor da commodity comercializada. As tarifas específicas são expressas com uma quantia fixa por unidade física da commodity comercializada; já a tarifa composta é uma combinação das tarifas ad valorem e específica. 
Todavia, as tarifas diminuíram nos últimos tempos, porque os governos preferem proteger suas indústrias por meio de barreiras não tarifárias, como forma de evitar sanções e discussões na OMC (KRUGMAN; OBSTFELD, 2005). A proteção com base nas barreiras não tarifárias passou a se chamar de novo protecionismo, em contraste com o velho protecionismo, que se baseava nas tarifas alfandegárias (WILLIANSON; MILNER, 1991).

As cotas, as restrições voluntárias às exportações, os subsídios às exportações e as novas barreiras comerciais, caso das técnicas, ecológicas, burocráticas e sanitárias são as principais barreiras não tarifárias utilizadas pelos países (AZÚA, 1986; MAIA, 2001). A cota é uma restrição quantitativa que limita as importações de determinadas commodities. Define-se restrição voluntária às exportações como um pedido do país importador ao país exportador no sentido de reduzir a quantidade de mercadorias exportadas a fim de evitar maiores sanções no âmbito macroeconômico internacional (KRUGMAN; OBSTFELD, 2005).

Os subsídios às exportações são pagamentos diretos, com concessão de isenção fiscal e empréstimos subsidiados aos exportadores das economias. Os subsídios também podem ocorrer na forma de empréstimos a juros baixos concedidos a compradores estrangeiros de maneira a estimular as exportações do país (SALVATO$\mathrm{RE}, 2000$ ).

Já as barreiras técnicas são mecanismos que as nações utilizam para proteger seu mercado, ou seja, o país só importará determinados produtos se seguir certos padrões, enquanto que as barreiras ecológicas têm como pretexto proteger a natureza. Entende-se por barreiras sanitárias a proibição da importação de determinadas mercadorias por considerar-se que esses produtos podem causar problemas à saúde da população (MAIA, 2001). Essas barreiras podem ser vistas como uma forma de as nações protegerem seus mercados.

\section{Metodologia}

Esta seção aborda o funcionamento: do Modelo de Equilíbrio Geral, das relações econômicas e do comportamento dos agentes, do fechamento macroeconômico do modelo e alocação do investimento entre regiões. Além disso, trata-se dos cenários analisados e da fonte de dados utilizados na pesquisa. 


\subsection{O Modelo de Equilíbrio Geral}

O modelo GTAP (Global Trade Analysis Project) é um modelo estático, multirregional e multissetorial, que agrega setores e bens, países e regiões, fatores de produção e de mobilidade livre dentro de uma dada região (trabalho qualificado, trabalho não qualificado e capital) e fatores de produção fixos (terra e outros recursos naturais) (GURGEL, 2007).

Os Modelos de Equilíbrio Geral são construídos sobre sólidas bases microeconômicas, já que é preciso definir os agentes (consumidores, produtores, governo e resto do mundo) por meio de equações de comportamento, além de apresentarem consistência interna entre todas as variáveis, uma vez que derivam de uma base de dados necessariamente consistente e coerente. Esses modelos fornecem soluções numéricas para todas as variáveis endógenas, o que possibilita analisar os efeitos de mudanças em políticas econômicas (FOCHEZATTO, 2005).

Os choques de políticas comerciais podem ser aplicados como a alteração de tarifas às importações e impostos às exportações. Essas alterações implicam mudança dos preços relativos de produtos importados e exportados, que afeta as demandas finais e intermediárias (GURGEL, 2002). A Figura 4 apresenta as inter-relações dos agentes do modelo.

Figura 4 - Economia multirregional e aberta

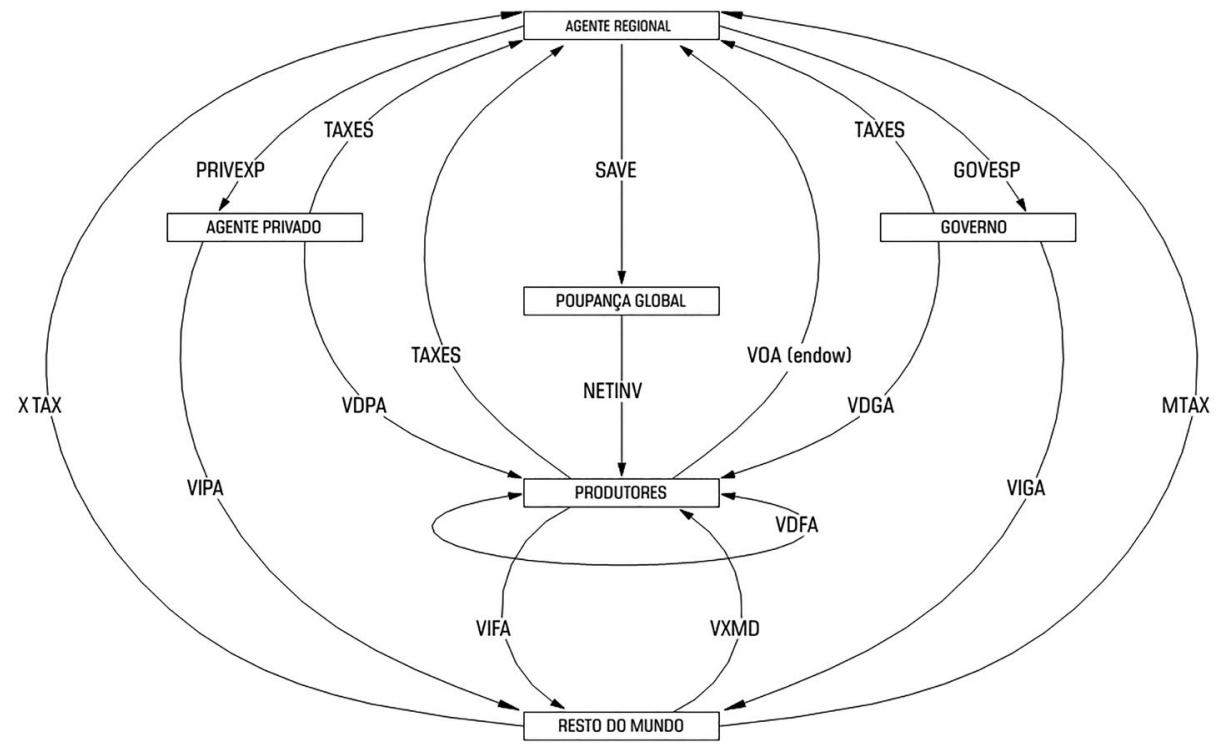

Fonte: Hertel e Tsigas (1997). 
Conforme a Figura 4, observa-se que a despesa do agente regional é dada por uma função de utilidade agregada, em que as despesas são alocadas entre consumo privado (PRIVEXP), consumo do governo (GOVESP) e poupança global (SAVE). A receita do agente regional é função da venda dos serviços dos fatores primários de produção, representado por VOA (valor do produto, a preços dos agentes) e pelos impostos TAXES (incididos sobre os bens domésticos), MTAX (tarifas à importação) e XTAX (taxas à exportação).

Os produtores têm suas receitas oriundas das vendas de sua produção aos agentes domésticos, que são os agentes privados (VDPA = valor das compras domésticas pelo setor privado, a preços de agente), o governo (VDGA = valor das compras domésticas do governo, a preços de agente), outras firmas (VDFA = consumo intermediário) e os agentes externos (resto do mundo, que representa a fonte de importação e o destino das exportações), por meio das exportações (VXMD). Ainda nesse contexto, a receita pode ser gerada pelo valor das vendas de bens de investimento para satisfazer à demanda de poupanças pelos agentes regionais (REGINV).

A receita dos produtores é gasta com consumo intermediário (VDFA), na aquisição de serviços dos fatores primários (VDPA), nas importações (VIFA) e no pagamento de impostos (TAXES) ao governo. Assim, toda receita gerada é despendida com a compra de fatores intermediários e serviços de fatores primários, o que permite a condição de lucro econômico zero, pressuposto do fechamento do modelo.

$\mathrm{O}$ governo e os agentes privados gastam suas rendas em produtos domésticos e importados, VIGA e VIPA, respectivamente, bem como ambos os agentes pagam impostos de importação (MTAX) e de consumo (TAXES) e poupam (SAVE). Os fluxos regionais de poupança são agregados em nível global (poupança global), que são distribuídos para investimento em cada região (MONTE; TEIXEIRA, 2007).

\subsection{Relações econômicas e comportamento dos agentes}

A tecnologia utilizada pelas firmas em cada indústria do modelo é caracterizada pela árvore tecnológica ou de produção, que representa as tecnologias de forma separada e com retornos constantes à escala. $\mathrm{O}$ fechamento macroeconômico do GTAP é do tipo neoclássico, no qual vigora a lei dos rendimentos constantes de escala (MONTE; TEIXEIRA, 2007). A Figura 5 ilustra a árvore de produção. 
Figura 5 - Árvore de produção

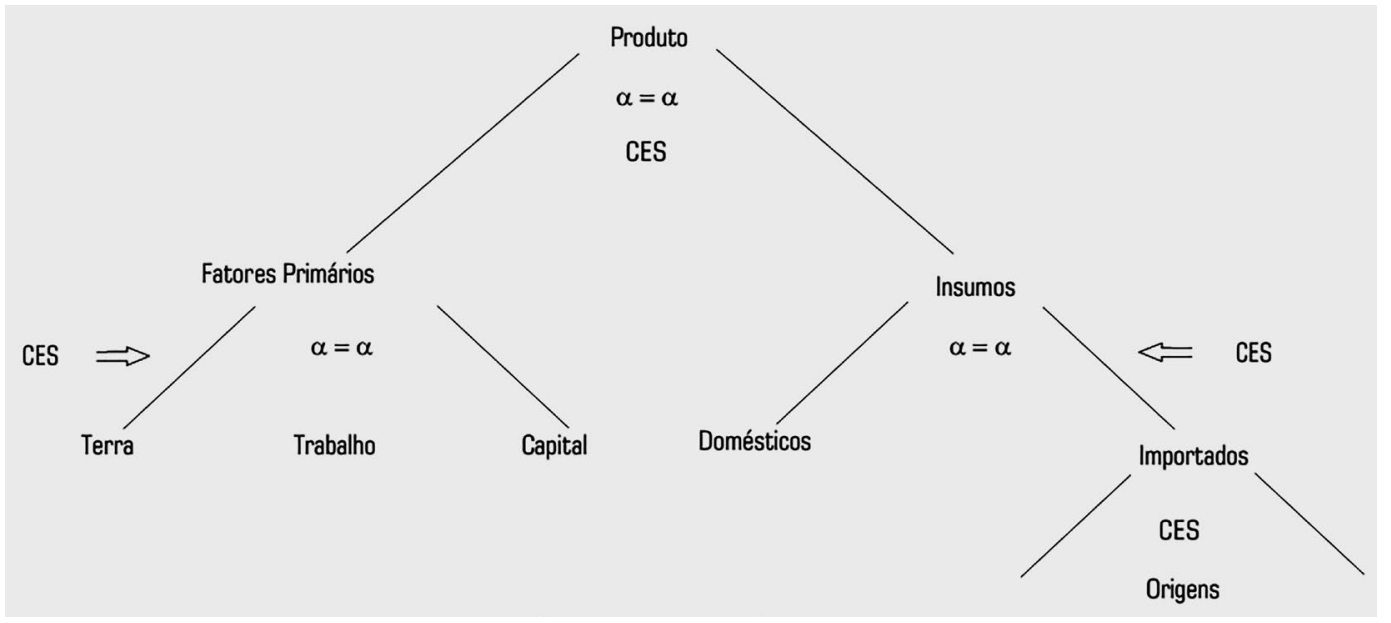

Fonte: Hertel e Tsigas (1997)

Admite-se que as firmas escolhem sua combinação ótima de fatores de produção independentemente dos preços dos insumos intermediários. Por admitir esse pressuposto da separabilidade, impõe-se que a elasticidade de substituição entre quaisquer dois fatores primários, de um lado, e entre quaisquer dois insumos intermediários, de outro, seja igual. Isso permite a obtenção da árvore de produção, pois, como sua elasticidade é comum, consegue-se traçar o primeiro nó da árvore, na qual insumos intermediários e fatores primários são combinados.

Dentro do grupo de fatores primários, as possibilidades de substituição reduzem-se a um único parâmetro, ou seja, admite-se uma função do tipo Elasticidade Constante de Substituição (CES), ${ }^{3}$ conforme a Equação 1:

$$
Q=A\left[\delta K^{-p}+(1-\delta)^{-p}\right]^{-1}
$$

em que $A>0 ; 0<\delta<1 ; p>-1$, em que $Q$ é a quantidade produzida; os fatores de produção $\mathrm{K}$ e L, o capital e trabalho. Os parâmetros $A, p$ e $\delta$ são um indicador do estado de tecnologia, o valor da constante da elasticidade de substituição, e o parâmetro de distribuição que se relaciona com as participações relativas dos fatores no produto, respectivamente.

Para funções do tipo CES, que possuem elasticidade de substituição constante e diferente da unidade, as mudanças percentuais na relação de preços 
refletem sempre a substitutibilidade dos bens ou fatores (MONTE; TEIXEIRA, 2007). Dada a Equação 1, tem-se a elasticidade de substituição na Equação 2:

$$
\sigma=\frac{1}{1+p}
$$

Substituindo-se (2) em (1), obtém-se a Equação 3:

$$
Q=A\left[\delta K^{-\frac{\sigma-1}{\sigma}}+(1-\delta)^{-\frac{\sigma-1}{\sigma}}\right]^{\frac{\sigma}{\sigma-1}}
$$

O fator terra é empregado apenas na atividade agrícola e é imperfeitamente móvel entre os setores, enquanto os fatores L e K são empregados em todos os setores e são considerados perfeitamente móveis em uma economia. A elasticidade de substituição entre os pares de fatores primários varia de atividade para atividade, mas não entre regiões.

Os fatores intermediários também admitem a separabilidade, isto é, a combinação ótima dos fatores intermediários também independe do preço dos fatores primários. Assume-se que a elasticidade parcial de substituição entre os fatores intermediários seja constante e igual a zero, isto é, a combinação entre eles ocorre em proporção fixa. Admite-se a separabilidade entre insumos domésticos e importados, ou seja, as firmas decidem a fonte de suas importações e, baseadas nos preços de importação, determinam a combinação ótima de insumos domésticos e importados.

Para a análise do comportamento dos indivíduos, verifica-se que o consumo regional é formado por uma função de utilidade agregada que depende do consumo privado (CP), das despesas do governo (CG) e da poupança (S). Assim, a renda regional é distribuída de acordo com a demanda final, do consumo privado, consumo do governo e da poupança, por meio de uma função de utilidade per capita Cobb-Douglas, de acordo com a Equação 4:

$$
U=K C P^{\theta C P} C G^{\theta C G} S^{\theta S}
$$

em que U é a utilidade total em cada região, $K$ e $\theta$ os parâmetros da função. A maximização da função utilidade determina a alocação da renda em cada região. $O$ fechamento padrão do GTAP faz com que a participação de cada um daqueles itens da demanda final na renda total seja constante, uma vez que a função de utilidade é uma Cobb-Douglas. 


\subsection{Fechamento macroeconômico do modelo e alocação do investimento entre regiões}

O GTAP não considera as políticas macroeconômicas e os fenômenos monetários, que são fatores explicativos do investimento agregado. Por não ser um modelo intertemporal e sequenciado no tempo, o investimento não é capaz de afetar a capacidade produtiva das indústrias/regiões. A alocação de investimentos entre as regiões afeta a produção e o comércio apenas por meio dos efeitos sobre a demanda final. Essas observações justificam a maior atenção dada a essa questão, além de o tratamento entre poupança e investimento ser necessário para completar o sistema econômico global, assegurando consistência no sistema de contas.

Além disso, é necessário lidar com mudanças potenciais na conta corrente. Geralmente, os procedimentos de fechamento forçam a convergência entre poupança e investimento doméstico, fixando o balanço da conta corrente, que pode ser expresso pela fixação do lado esquerdo da identidade das contas nacionais, como segue:

$$
S-I \equiv X+R-M
$$

em que S representa a poupança; I, o investimento; X, as exportações; $M$, as importações e R, as transferências internacionais.

No lado direito da identidade citada será assegurada a igualdade entre poupança e investimento global, mesmo sem presença de um banco global para fazer a intermediação. Essa abordagem representa um fechamento de equilíbrio neoclássico, uma vez que o investimento é forçado a se alinhar às mudanças regionais da poupança.

\subsection{Cenários analisados}

Definiram-se dois cenários analíticos. O primeiro supõe a mensuração dos efeitos da liberalização comercial completa, com a eliminação total das barreiras tarifárias, dos subsídios à produção e exportação, como também a eliminação das barreiras não tarifárias. O segundo supõe a redução de tarifas de importação e de subsídios à produção bem como eliminação dos subsídios à exportação, conforme proposto pela Organização Mundial do Comércio na Rodada de Doha.

Para as tarifas de importação, as reduções propostas pela Rodada de Doha valem para os produtos agrícolas e manufaturados, para as quais as simulações 
observaram o Método de Girard ou a fórmula suíça. Esse método resulta em maiores reduções em tarifas mais elevadas do que em tarifas menores, obtendo, assim, uma harmonização tarifaria (PEREIRA; TEIXEIRA; GURGEL, 2009). A Tabela 1 aborda a redução tarifária proposta pela fórmula suíça.

Tabela 1 - Proposta de redução de tarifa para produtos agrícolas (Método de Girard)

\begin{tabular}{c|r|c}
\hline Grupo & Tarifas atuais & Redução proposta \\
\hline 1 & $0-20 / 30 \%$ & $20 \%-65 \%$ \\
2 & $20 / 30 \%-40 / 60 \%$ & $30 \%-75 \%$ \\
3 & $40 / 60 \%-60 / 90 \%$ & $35 \%-85 \%$ \\
4 & $>60 / 90 \%$ & $42 \%-90 \%$ \\
\hline
\end{tabular}

Fonte: Organização Mundial do Comércio (2005).

Este método recomenda cortes maiores sobre tarifas de importação mais elevadas e estabelece um nível máximo de tarifas. Aplica-se o limite inferior de cada grupo, isto é, redução de 20\% para países do Grupo 1, 30\% para o Grupo 2; para países com tarifas nos níveis do Grupo 3, aplicou-se redução de $35 \%$ e redução de $42 \%$ para países com tarifas atuais superiores a $60 \%$, do Grupo 4 . A redução proposta para os instrumentos comerciais apresentados acima compõem o cenário I (SONAGLIO; BENDER FILHO; TEIXEIRA, 2009).

No caso proposto, as barreiras para o setor de frutas, vegetais e nozes é inferior a $10 \%$ para todos os destinos analisados (GLOBAL TRADE ANALYSIS PROJECT, 2014), portanto, aplica-se a redução proposta em seu limite inferior, $20 \%$.

A redução nos subsídios à produção agropecuária segue a proposta da $\mathrm{OMC}$, que sugere a redução dos subsídios de acordo com o valor total de subsídios concedidos pelos países/regiões. Dessa forma, divide-se a economia mundial em três grupos, conforme se observa na Tabela 2.

Tabela 2 - Proposta da OMC para redução dos subsídios à produção agrícola

\begin{tabular}{c|c|c}
\hline Grupo & Gastos em US\$ bilhões & Redução proposta \\
\hline 1 & $0-10$ & $31 \%$ \\
2 & $10-60$ & $53 \%$ \\
3 & $>60$ & $70 \%$ \\
\hline
\end{tabular}

Fonte: Organização Mundial do Comércio (2005).

No Grupo 1, encontram-se os países que concedem subsídios de até US\$ 10 bilhões anuais, para o qual a proposta de redução é de $31 \%$. No Grupo 2, encontram-se 
os países com gastos em subsídios à produção entre US $\$ 10$ e US $\$ 60$ bilhões anuais, para esses, a proposta de redução chega a 53\%. No grupo 3, estão os países com gastos superiores a US $\$ 60$ bilhões ao ano, e a redução proposta para os países integrantes desse grupo é de 70\%. No Grupo 2, destacam-se os Estados Unidos e no Grupo 3 a União Europeia. Os demais países/regiões analisadas encontram-se no Grupo 1.

Em relação aos subsídios à exportação de produtos agropecuários, a proposta da OMC é mais enfática, uma vez que propõe a eliminação completa desse tipo de barreira de comércio. Cabe destacar que ambos os cenários avaliam apenas os efeitos de alterações na política comercial europeia para os produtos do setor de hortifrúti brasileiro. Não foram realizados choques nas políticas comerciais nas demais regiões devido aos objetivos propostos.

\subsection{Fonte de dados}

O banco de dados utilizado é o do Global Trade Analysis Project, versão 8, com base de dados para 2004 e 2007. Essa versão compreende 129 regiões $^{4}$ e 57 setores/ commodities. A Tabela 3 agrega as principais regiões e mais importantes setores que foram analisados.

Tabela 3 - Agregação entre regiões e setores realizadas no GTAP

\begin{tabular}{l|l}
\hline \multicolumn{1}{c|}{ Regiões } & \multicolumn{1}{c}{ Setores } \\
\hline Brasil (BRA) & \\
MERCOSULex, exceto Brasil, (MERex) & Vegetais, frutas e nozes \\
Estados Unidos (EUA) & Outros setores \\
União Europeia 25 (EUR) & \\
BRICex, ${ }^{5}$ exceto Brasil, (BRICex) & \\
Resto do mundo (RDM) & \\
\hline
\end{tabular}

Fonte: elaborada a partir do GTAP-8.

Obs.: os símbolos entre parênteses indicam os códigos que serão utilizados para a estimação na análise e discussão dos resultados.

A agregação dessas regiões justifica-se na medida em que os Estados Unidos e a União Europeia representam parcela significativa das exportações brasileiras de frutas, atingindo aproximadamente $86,10 \%$ em 2013 (ANÁLISE DAS INFORMAÇÕES DE COMÉRCIO EXTERIOR, 2013). Os países do BRICs, exceto o Brasil, representa o comportamento dos países em desenvolvimento, com ênfase para China e Índia, que são os maiores produtores mundiais de frutas (ANDRADE, 2012). 


\section{Análise e discussão dos resultados}

Esta seção trata dos dois cenários da pesquisa. Primeiramente, discute-se a liberalização completa do comércio entre União Europeia e Brasil para o setor de frutas e vegetais. Posteriormente, faz-se a análise com a implementação do cenário proposto pela Rodada de Doha, com reduções das barreiras comerciais entre as duas regiões para o setor de hortifrúti.

\subsection{Análise do cenário 1}

Em um cenário de eliminação completa das barreiras tarifárias e não tarifárias pela União Europeia para as frutas, os vegetais e as nozes brasileiras, de acordo com a Tabela 4, verificam-se mudanças mais acentuadas na quantidade produzida do Brasil e do bloco europeu. A quantidade produzida por esse setor eleva-se para 3,53\%, no caso brasileiro, devido às condições menos restritivas de acesso ao mercado e consequente aumento na demanda. Há queda na produção europeia de hortifrúti, em torno de $0,82 \%$, em função da eliminação de subsídios de produção e da realocação produtiva do setor, dos países menos eficientes para os mais eficientes.

Em termos de exportações, observa-se crescimento de 15,24\% das exportações do Brasil e queda de $0,63 \%$ das exportações europeias, ou seja, a eliminação completa dos entraves ao comércio brasileiro de hortifrúti para a União Europeia desestimula as exportações desse destino em prol do crescimento das exportações desses produtos realizadas pelo Brasil, conforme a Tabela 4. Assim, pode-se sugerir que a eliminação completa das barreiras tarifárias e não tarifárias para as frutas e vegetais brasileiros causa um efeito de criação de comércio, uma vez que há aumento da quantidade produzida e exportada desses bens do Brasil, e redução da produção e exportação da União Europeia, sugerindo, portanto, maior fluxo comercial entre ambos a partir desse cenário.

Além disso, esse resultado permite inferir que parte do crescimento do setor brasileiro é restringida pelo protecionismo praticado pelo bloco europeu, seriam necessárias ações estratégicas de negociação com o intuito de reduzir ou eliminar as barreiras comerciais bem como de inserir e adequar o produto brasileiro às normas de qualidade europeias. Ressalta-se que as mudanças nas exportações geralmente acompanham as mudanças na produção, com algumas poucas exceções (GURGEL, 2007).

Nota-se a falta de competitividade europeia nesse setor em um cenário de liberalização de comércio, o que permite supor que os subsídios à produção, à exportação e tarifas de importação são alguns dos mecanismos que mantêm o setor de 
hortifrúti europeu. Verifica-se que os BRICex, os EUA e o MERCOSULex também ampliariam suas exportações nesse cenário, embora em menores porcentagens.

De acordo o que é apresentado na Tabela 4, em termos de importações, observa-se que a União Europeia ampliaria suas importações de hortifrúti em 0,59\% e o Brasil em 0,42\%. Esse resultado é a contrapartida dos resultados da produção e da exportação, uma vez que o país aumentaria sua competitividade em frutas e vegetais, em alguns produtos do setor, mais especificamente, em detrimento da importação de outros produtos também do setor. Esse aspecto pode ser justificado por um tipo de comércio intrassetorial entre os países, entre as diferentes variedades de frutas e vegetais, se cultivadas em clima tropical ou temperado.

Além disso, pode-se evidenciar que houve um aumento mais do que proporcional da quantidade exportada em relação à quantidade de frutas e vegetais produzida pelo Brasil, indicando que o crescimento da demanda externa não foi suprido pelo incremento de oferta brasileira, acarretando maior absorção do produto brasileiro. Assim, o país pode vir a recorrer ao mercado externo para suprir parte do seu mercado nacional, o que pode ser verificado na Tabela 4 .

Tabela 4 - Mudanças na quantidade produzida (qo), exportações (vxwfob), importações (viwcif), preços domésticos (pm) e no bem-estar dos consumidores (ev) em um cenário de liberalização completa do comércio europeu para as exportações brasileiras do setor, em variações percentuais (\%)

\begin{tabular}{|c|c|c|c|c|c|c|}
\hline & \multicolumn{6}{|c|}{ Variação na quantidade produzida } \\
\hline & BRA & BRICex & EUA & MERex & UE & RDM \\
\hline FVN & 3,53 & 0,02 & 0,08 & 0,15 & $-0,82$ & 0,09 \\
\hline \multirow[t]{3}{*}{ Out. setores } & $-0,01$ & 0,00 & 0,00 & 0,00 & 0,00 & 0,00 \\
\hline & \multicolumn{6}{|c|}{ Variação no valor das exportações } \\
\hline & BRA & BRICex & EUA & MERex & UE & RDM \\
\hline FVN & 15,24 & 0,43 & 0,50 & 0,72 & $-0,63$ & 0,52 \\
\hline \multirow[t]{3}{*}{ Out. setores } & $-0,07$ & 0,00 & 0,00 & $-0,01$ & 0,01 & 0,00 \\
\hline & \multicolumn{6}{|c|}{ Variação no valor das importações } \\
\hline & BRA & BRICex & EUA & MERex & UE & RDM \\
\hline FVN & 0,42 & $-0,12$ & 0,00 & 0,02 & 0,59 & $-0,04$ \\
\hline \multirow[t]{3}{*}{ Out. setores } & 0,03 & 0,00 & 0,00 & 0,00 & 0,00 & 0,00 \\
\hline & \multicolumn{6}{|c|}{ Variação nos preços domésticos } \\
\hline & BRA & BRICex & EUA & MERex & UE & RDM \\
\hline FVN & 0,34 & 0,01 & 0,02 & 0,03 & 0,63 & 0,02 \\
\hline \multirow[t]{4}{*}{ Out. setores } & 0,01 & 0,00 & 0,00 & 0,00 & 0,00 & 0,00 \\
\hline & \multicolumn{6}{|c|}{ Mudanças no bem-estar dos consumidores* } \\
\hline & BRA & BRICex & EUA & MERex & UE & RDM \\
\hline & 23,23 & $-59,92$ & $-2,83$ & $-0,14$ & 149,80 & $-44,44$ \\
\hline
\end{tabular}

Fonte: elaborada pelos autores. 
Quanto aos preços, observam-se elevações de 0,34\% e 0,63\% dos preços domésticos do setor de frutas e vegetais do Brasil e da União Europeia, considerando a eliminação total de barreiras tarifárias e não tarifárias das exportações do Brasil para a União Europeia. Para o bloco europeu, a redução na quantidade produzida internamente acarreta uma menor oferta doméstica, o que pressiona a suba de preços.

No caso brasileiro, pode-se sugerir que a demanda externa é superior à oferta desses produtos, o que pressiona a elevação de preços. Tais aumentos referem-se ao crescimento da demanda pelos produtos exportados pelo Brasil no mercado externo, uma vez que esses produtos são relativamente mais protegidos no restante do mundo do que no Brasil (GURGEL, 2007).

Para o primeiro cenário, destacam-se mudanças mais significativas de bem-estar para os consumidores europeus do que para os brasileiros, em torno de $149,80 \%$. A queda das barreiras comerciais possibilita maior eficiência, por meio da alocação dos insumos e fatores produtivos, na produção e no comércio internacional do setor de hortifrúti, o que acarreta incremento de bem-estar para a população.

\subsection{Análise do cenário 2}

Os resultados obtidos pelas simulações para produção, preços, bem-estar dos consumidores e fluxos comerciais internacionais decorrentes da proposta realizada na Rodada de Doha estão representados na Tabela 5.

Em um cenário de eliminação parcial, considerando a redução das barreiras tarifárias e não tarifárias pela União Europeia para frutas, vegetais e nozes brasileiras, observa-se crescimento na quantidade produzida pelo Brasil e decréscimo na produção europeia, $0,83 \%$ e $0,54 \%$, respectivamente. A redução das barreiras comerciais permitiu a ampliação da produção brasileira, visto que há vantagens comparativas na produção (CORONEL et al., 2014). Para o mercado europeu, há um desestímulo do setor produtivo, dada a redução dos subsídios à produção.

De acordo com os dados da Tabela 5 , verifica-se crescimento de $3,52 \%$ das exportações brasileiras de frutas brasileiras devido à queda das barreiras comerciais para o destino em questão. Dessa forma, verifica-se que o Brasil tende a ganhar com a redução de barreiras comerciais da UE (GURGEL, 2007). Além disso, observa-se crescimento de $0,36 \%, 0,42 \%, 0,56 \%$ e $0,43 \%$ nas exportações do BRICex, EUA, MERCOSULex e RDM, respectivamente. O cenário mais próximo do livre comércio permite que as regiões que possuam vantagens na produção intensifiquem suas exportações. Por outro lado, pode-se destacar a redução de 0,38\% nas 
exportações europeias, o que sugere a queda de competitividade deste setor quando se reduz os mecanismos de proteção do mercado.

Tabela 5 - Mudanças na quantidade produzida (qo), exportações (vxwfob), importações (viwcif), preços domésticos $(\mathrm{pm})$ e no bem-estar dos consumidores (ev) em um cenário proposto pela Rodada de Doha do comércio europeu para as exportações brasileiras do setor, em variações percentuais (\%)

\begin{tabular}{|c|c|c|c|c|c|c|}
\hline & \multicolumn{6}{|c|}{ Variação na quantidade produzida } \\
\hline & BRA & BRICex & EUA & MERex & UE & RDM \\
\hline FVN & 0,83 & 0,02 & 0,06 & 0,11 & $-0,54$ & 0,08 \\
\hline \multirow[t]{3}{*}{ Out. setores } & 0,00 & 0,00 & 0,00 & 0,00 & 0,00 & 0,00 \\
\hline & \multicolumn{6}{|c|}{ Variação no valor das exportações } \\
\hline & BRA & BRICex & EUA & MERex & UE & RDM \\
\hline FVN & 3,52 & 0,36 & 0,42 & 0,56 & $-0,38$ & 0,43 \\
\hline \multirow[t]{3}{*}{ Out. setores } & $-0,02$ & 0,00 & 0,00 & $-0,01$ & 0,00 & 0,00 \\
\hline & \multicolumn{6}{|c|}{ Variação no valor das importações } \\
\hline & BRA & BRICex & EUA & MERex & UE & RDM \\
\hline FVN & 0,09 & $-0,11$ & 0,00 & 0,03 & 0,39 & $-0,03$ \\
\hline \multirow[t]{3}{*}{ Out. setores } & 0,01 & 0,00 & 0,00 & 0,00 & 0,00 & 0,00 \\
\hline & \multicolumn{6}{|c|}{ Variação nos preços domésticos } \\
\hline & BRA & BRICex & EUA & MERex & UE & RDM \\
\hline FVN & 0,08 & 0,01 & 0,01 & 0,02 & 0,45 & 0,02 \\
\hline \multirow[t]{4}{*}{ Out. setores } & 0,00 & 0,00 & 0,00 & 0,00 & 0,00 & 0,00 \\
\hline & \multicolumn{6}{|c|}{ Mudanças no bem-estar dos consumidores* } \\
\hline & BRA & BRICex & EUA & MERex & UE & RDM \\
\hline & 5,21 & $-51,86$ & $-1,40$ & 0,86 & 108,69 & $-37,97$ \\
\hline
\end{tabular}

Fonte: elaborada pelos autores.

Nesse caso, assim como no cenário anterior, pode-se sugerir também a criação de comércio, em que o setor brasileiro de hortifrúti amplia sua produção e exportação, devido à redução das barreiras comerciais, em detrimento da redução da produção e exportação do bloco europeu.

Verificou-se a variação positiva no valor das importações de frutas de $0,09 \%$ do Brasil e 0,39\% da União Europeia. Para essa última, a eliminação de parte da proteção do setor torna seus produtos menos competitivos e há a procura por produtos mais baratos, oriundos de outros mercados, o que acarreta a elevação dos preços desse setor em $0,45 \%$, o que corrobora a informação anterior. 
Para o BRICex e RDM, observa-se redução no valor importado de frutas e vegetais de $0,11 \%$ e $0,03 \%$, respectivamente. Para o primeiro, com o atual cenário, houve ampliação da quantidade produzida, aumento das exportações e queda das importações, devido ao maior suprimento do mercado interno. Para o segundo cenário, as mudanças foram mais significativas em termos de bem-estar para os consumidores europeus do que para os brasileiros, em torno de $108,69 \%$. A queda das barreiras comerciais possibilita maior eficiência no comércio internacional do setor, o que permite o incremento de bem-estar para a população.

Além disso, pode-se verificar que o cenário de liberalização total do comércio de frutas e vegetais do Brasil para o bloco europeu apenas influenciou na magnitude da variação das variáveis analisadas, se comparado com o cenário proposto na Rodada de Doha. Em ambos os cenários, os sinais encontrados para cada variável e região foram, de forma geral, similares.

Para um cenário de liberalização tarifária completa entre os blocos do Mercosul e União Europeia e para todas as regiões do mundo por meio da Rodada de Doha, Gurgel (2007) evidenciou aumentos dos preços domésticos e das importações para o setor de frutas e vegetais, o que corrobora com os resultados encontrados. Contudo, encontrou-se queda das exportações brasileiras de frutas e vegetais e do valor de produção setorial, e esses últimos resultados vão de encontro ao identificado no presente trabalho.

Porém, sugere-se que os diferentes níveis de agregação regional e choques nas reduções de barreiras e subsídios podem causar algum viés na comparação. Gurgel (2007) analisou o cenário de liberalização somente tarifária, ou apenas eliminação de subsídios domésticos ou eliminação dos subsídios às exportações, de forma desagregada, ao passo que neste estudo foi considerada como liberalização comercial a eliminação completa de tarifas às importações e de subsídios à exportação e à produção de forma conjunta. Além disso, o cenário analisado aplica as condições propostas pela Rodada de Doha, mas somente para o comércio de frutas e vegetais brasileiros ao bloco europeu, e não para toda a economia mundial.

Já Sampaio e Sampaio (2009) encontraram o saldo negativo para a balança comercial de frutas e vegetais, quando analisados os fatores abertura ampla na OMC e negociação entre o Mercosul e a União Europeia (Mercoeuro). Contudo, a agregação supõe a eliminação total das tarifas de importação e exportação, para os países envolvidos, mas com manutenção de subsídios domésticos à produção de produtos primários, a insumos agrícolas e a pagamentos à terra e ao capital. 


\section{Conclusões}

Este trabalho buscou analisar os possíveis impactos das políticas comerciais da União Europeia, como eliminação e redução de barreiras tarifárias e não tarifárias, para o setor exportador brasileiro de frutas e vegetais. Foram analisados dois cenários, o primeiro de liberalização do comércio europeu de frutas e vegetais com eliminação total de tarifas de importação, subsídios à produção e à exportação. $\mathrm{O}$ segundo cenário propõe a redução de tarifas de importação e subsídios à produção e eliminação de subsídios à exportação da UE para com os produtos do hortifrúti brasileiro, conforme proposto pela Rodada de Doha.

Destaca-se que, em ambos os cenários analisados, houve crescimento da quantidade produzida e exportada pelo Brasil, em detrimento da redução desses quantitativos para a União Europeia. Este fato corrobora a teoria, pois, em uma situação de maior liberalização comercial, o país que possuir vantagem na produção e exportação de determinado setor intensifica sua produção e exportação, como é o caso do Brasil para as frutas e vegetais. De outro lado, a região mais ineficiente reduz a produção e a exportação em uma situação de queda do protecionismo, caso do mercado europeu.

Além disso, verificou-se crescimento das importações e do preço doméstico desses produtos para os mercados brasileiro e europeu. Esse resultado é consistente com a intensificação dos fluxos de comércio, dado que, em uma situação de ampliação do livre comércio, as importações tendem a se expandir. A maior demanda pelos produtos brasileiros de hortifrúti e a baixa capacidade de expansão da oferta no curto prazo ampliam os preços desses bens no mercado nacional. No mercado europeu, a queda na produção do mercado doméstico, em função da eliminação ou redução dos incentivos do setor, reduz a oferta, ocasionando a elevação dos preços. Houve melhoria significativa nas condições de bem-estar dos consumidores brasileiros e europeus em função da eliminação e redução das barreiras comerciais.

Embora os resultados tenham mostrado consistência, pode-se ressaltar como limitação o fato de não ter sido incorporado o equivalente tarifário correspondente às barreiras não tarifárias, como as barreiras fitossanitárias. Para pesquisas futuras, sugere-se uma análise incorporando alterações no fechamento do modelo, tais como alguns procedimentos de calibração, considerando a possibilidade de ocorrência de desemprego e economias de escala, o que permite maior aproximação com a estrutura analítica e sistêmica dos setores analisados. 


\title{
El impacto de la política comercial de la Unión Europea sobre las exportaciones brasileñas de horticultura
}

\author{
Resumen
}

Este estudio tiene como objetivo analizar los efectos de la reducción de las barreras comerciales de la Unión Europea para las exportaciones brasileñas de frutas, verduras y nueces, concretamente, sobre la eliminación de las barreras arancelarias y no arancelarias. Con este fin, se hizo uso del Modelo de Equilibrio General Computable. Se simularon dos escenarios: la liberalización completa y la reducción de las barreras comerciales a las exportaciones de horticultura de Brasil a Unión Europea según lo propuesto por la ronda de Doha. Los resultados indicaron que, para Brasil, en ambos escenarios, hay un crecimiento de la cantidad producida, de las exportaciones e importaciones, y de los precios de la industria nacional de horticultura.

Palabras clave: Exportaciones. Frutas. Verduras. Unión Europea. GTAP.

\section{The impact of the European Union's trade policies on the exports of brazilian fruits and vegetables}

\begin{abstract}
This study aims to analyze the effects of reducing the European Union's trade barriers for the Brazilian export sector of fruits, vegetables and nuts, specifically regarding the elimination of tariff and non tariff barriers. In order to accomplish this, the Computable General Equilibrium Model was used, and two situations were simulated: the complete liberalization and reduction of trade barriers, as proposed by the Doha round, of the export of fruits and vegetables from Brazil to the European Union. The results indicated that, for Brazil, in both scenarios, there is an increase in relation to the quantity produced, the exports and imports and the domestic prices of the fruits and vegetables sector.
\end{abstract}

Keywords: Exports. Fruits. Vegetables. European Union. GTAP. 


\section{Notas}

1 O General Agreement on Tariffs and Trade, criado em 1947, era um acordo que tinha como objetivo diminuir as barreiras comerciais entre os signatários. Em 1994, esse acordo foi transformado na Organização Mundial do Comércio, que detém mecanismos destinados a resolver disputas comerciais.

2 Moreira (2010) e Barcellos Neto (2002) divergem quanto aos estágios de integração regional:,o primeiro suprime o estágio de acordos preferenciais de comércio e o segundo autor não aborda o estágio da integração econômica total. Krugman e Obstfeld (2005) não apontam os três últimos estágios de integração regional.

3 A sigla CES refere-se a Constant Elasticity of Substitution.

4 Para mais detalhes sobre quais países e quais produtos estão inseridos na base de dados do modelo, acesse o endereço eletrônico <https://www.gtap.agecon.purdue.edu/databases/v8/>.

5 BRICs, bloco formado pelos países em desenvolvimento: China, Rússia, Índia e Brasil.

\section{Referências}

ANÁLISE DAS INFORMAÇÕES DE COMÉRCIO EXTERIOR. Alice Web. Consultas. 2013. Disponível em: <http://aliceweb2.mdic.gov.br/>. Acesso em: 2 fev. 2014.

ANDRADE, P. F. S. Análise da conjuntura agropecuária: safra 2011/12. fev. 2012. Disponível em: <http://www.agricultura.pr.gov.br/arquivos/File/deral/Prognosticos/fruticultura_2011_12.pdf>. Acesso em: 2 nov. 2014.

AZÚA, D. E. R. O neoprotecionismo e o comércio exterior. São Paulo: Aduaneiras, 1986.

BALDWIN, R. The political economy of trade. Journal of Economic Perspectives, Pittsburgh, v. 3, n. 4, p. 119-135, 1989.

BARCELLOS NETO, P. C. F. Impactos comerciais da Área de Livre Comércio das Américas: uma aplicação do modelo gravitacional. Dissertação (Mestrado em Ciências Econômicas) - Universidade Federal do Rio Grande do Sul, Porto Alegre, 2002.

BOTEON, M. Desafios da horticultura nacional. Hortifruti Brasil. 2006. Disponível em: <http:// www.cepea.esalq.usp.br/pdf/apresentacao_hortitec_jun06.pdf>. Acesso em: 21 set. 2014.

BRUM, A. L.; HECK, C. R. Economia internacional: uma síntese da análise teórica. Ijuí: Unijuí, 2005.

CAVES, R.; FRANKEL, J.; JONES, R. Economia internacional: comércio e transações globais. 6. ed. São Paulo: Saraiva, 2001.

CIOCHETTO, C. R.; ORLANDI, S. P.; VIEIRA, M. F. A. Consumo de frutas e vegetais em escolares da rede pública no Sul do Brasil. Archivos latino americanos de nutrición, Caracas, v. 62, n. 2, p. 172-178, 2012.

CORONEL, D. A. Fontes de crescimento e orientação regional das exportações do complexo soja brasileiro. Dissertação (Mestrado em Agronegócios) - Universidade Federal do Rio Grande do Sul, Porto Alegre, 2008.

CORONEL, D. A. et al. Competitividade das exportações nordestinas de frutas para a União Europeia (1999-2013). In: CONGRESSO DA SOCIEDADE BRASILEIRA DE ECONOMIA, ADMINISTRAÇÃO E SOCIOLOGIA RURAL, 52. Anais... Goiânia, 2014. 
CRUVINEL, P. E. O agronegócio e oportunidades para o desenvolvimento sustentável no Brasil. São Carlos: Embrapa Instrumentação Agropecuária, 2009. (Embrapa Instrumentação Agropecuária. Documentos 44).

FOCHEZATTO, A. Modelos de equilíbrio geral aplicados na análise de políticas fiscais: uma revisão de literatura. Análise Revista de Administração da PUCRS, Porto Alegre, v. 16, n. 1, p. 113-136, 2005.

GLOBAL TRADE ANALYSIS PROJECT. GTAP 8 Data Base. 2014. Disponível em: <https:// www.gtap.agecon.purdue.edu/databases/v8/default.asp>. Acesso em: 26 jul. 2014.

GURGEL, A. C. Impactos econômicos e distributivos de mudanças nas relações comerciais da economia brasileira na presença de economias de escala. Tese- (Doutorado em Economia Aplicada) - Universidade Federal de Viçosa, Viçosa, 2002.

GURGEL, A. C. Impactos da integração comercial sobre a agricultura familiar no Brasil. Pesquisa e Planejamento Econômico, Rio de Janeiro, v. 37, n. 1, p. 21-74, 2007.

HERTEL, T. W.; TSIGAS, M. E. Structure of GTAP. In: HERTEL, T. W. (Ed.). Global trade analysis: modeling and applications. New York: Cambridge University, p. 13-73, 1997.

JAIME, P. C.; MONTEIRO, C. A. Fruit and vegetable intake by Brazilian adults, 2003. Cadernos de Saúde Pública, Rio de Janeiro, v. 21, n. 1, p. 19-24, 2005.

KRUGMAN, P.; OBSTFELD, M. Economia internacional. 6. ed. São Paulo: Pearson Education do Brasil, 2005. 558 p.

MAIA, J. M. Economia internacional e comércio exterior. São Paulo: Atlas, 2001.

MAGEE, S. Endogenous protection: the empirical evidence. In: MUELLER, Dennis C. (ed.). Perspectives on public choice: a handbook. New York: Cambridge University, 1997. p. 425-561.

MONTE, E. Z.; TEIXEIRA, E. C. Impactos da Área de Livre Comércio das Américas (Alca), com gradual desgravação tarifária, na economia brasileira. Nova Economia, Belo Horizonte, n. 17, v. 1, p. 37-63, jan./abr., 2007.

MORAIS, A. G. Criação e desvio de comércio no Mercosul e no Nafta. Dissertação (Mestrado em Economia) - Universidade de São Paulo, São Paulo, 2005.

MOREIRA, C. S. A integração regional como resposta ao processo de globalização. Gestão Contemporânea, Porto Alegre, v. 7, p. 215-243, 2010.

OLIVEIRA, C. M.; CARDOSO, B. F.; LÍRIO, V. S.; MIRANDA, A. C. O Brasil no mercado internacional de leite em pó: padrão, criação e desvio de comércio no Mercosul. In: CONGRESSO DA SOCIEDADE BRASILEIRA DE ECONOMIA, ADMINISTRAÇÃO E SOCIOLOGIA RURAL, 47. Porto Alegre. Anais... Porto Alegre, jul. 2009.

ORGANIZAÇÃO MUNDIAL DO COMÉRCIO. Doha work program: preparations for the sixth session of the ministerial conference draft ministerial text. 2005. Disponível em: <https://www. wto.org/english/thewto_e/minist_e/min05_e/draft_min05_text_e.doc>. Acesso em: 8 jun. 2009.

PEREIRA, M. W. G.; TEIXEIRA, E. C.; GURGEL, A. C. Os custos do fracasso das negociações da Rodada de Doha para as regiões brasileiras. In: ILHA, A. S.; FREITAS, C. A. (Org.). O agronegócio brasileiro e o comércio internacional. Curitiba: CRV, 2009. p. 151-179.

RUBIN, L. S. O comércio brasileiro de carnes no contexto de integração regional. Dissertação (Mestrado em Integração Latino-Americana) - Universidade Federal de Santa Maria, Santa Maria, 2005. 
SALVATORE, D. Economia internacional. 6. ed. Rio de Janeiro: Livros Técnicos e Científicos S.A., 2000. 436 p.

SAMPAIO, L. M. B.; SAMPAIO, Y. Prioridade brasileira entre acordos de livre comércio utilizando equilíbrio geral aliado à teoria dos jogos. EconomiA, Brasília, v. 10, p. 533-551, 2009.

SONAGLIO, C. M.; BENDER FILHO, R.; TEIXEIRA, E. C. Impactos da Rodada Doha sobre o agronegócio brasileiro. In: CONGRESSO DA SOCIEDADE BRASILEIRA DE ECONOMIA, ADMINISTRAÇÃO E SOCIOLOGIA RURAL, 47. Anais... Porto Alegre, 2009.

ROBSON, P. Teoria econômica da integração internacional. 2. ed. Coimbra: Coimbra Editora, 1985.

VASCONCELOS, C. R. F. Criação e desvio de comércio: análise do fluxo comercial entre Brasil e Mercosul para alguns produtos industrializados. Análise econômica, Porto Alegre, n. 36, set. 2001.

VIEIRA, N. M.; O setor agroexportador brasileiro e os investimentos diretos externos no contexto da integração Mercosul / UE. Dissertação (Mestrado em Economia Aplicada) - Universidade Federal de Viçosa, Viçosa, 2006.

VINER, J. The customs union issue. New York: Carnegie Endowment for International Peace, 1950 .

WILLIANSON, J.; MILNER, C. The word economy: a textbook in international economics. London: Harvestar Wheatsheaf, 1991. 